\title{
Cultural factors related to the decision of music education career choice in Jewish and Arab students in Israel
}

\author{
Rona Poles Cahn ${ }^{\mathrm{a}, \mathrm{b}, *}$, Alina S. Rusu ${ }^{\mathrm{a}, \mathrm{c}}$ \\ ${ }^{a}$ Doctoral School "Education, Reflection, Development”, Babes-Bolyai University, Sindicatelor 7 \\ Street, 400029, Cluj-Napoca, Cluj, Romania \\ ${ }^{b}$ Department of Music Education, Levinsky College of Education, Tel Aviv, Israel. \\ ${ }^{c}$ Faculty of Animal Sciences and Biotechnologies, University of Agricultural Sciences and Veterinary \\ Medicine, Calea Mănăștur Street, 400372, Cluj-Napoca, Romania
}

\begin{abstract}
The decision to become a music educator can be influenced by the musical background of an individual, the cultural values, and by the perceived utilitarian value in terms of viable career option. This study was conducted among Jewish and Arab music-education students in Israel. The aim was to identify aspects related to choosing a career in music, particularly culturally shaped attitudes and perceptions. Cultural differences were examined using the Cultural Attitudes toward Music Experience and Education (CAMEE) questionnaire. Participants were 50 Israeli Jewish and Arab students who were enrolled in music education programs. Findings showed culturally related differences between participants' musical upbringing. The Jewish students reported that they listened mainly to Westernstyle genres, played Western-type instruments, and studied Western music theory. The Arab students listened mainly to Middle Eastern Arab-style genres, played mainly music instruments that enable playing Arab music, and studied Middle Eastern Arab music theory. The Jewish students reported more experience with music and instrumental playing than their Arab peers. Motivation for teaching music included educational and ideological components for both groups, with Arab students reporting a higher level of utilitarian motivation.
\end{abstract}

Keywords: cultural affiliation; music education in Israel; family musical background.

\section{Introduction}

Cultural affiliation is established during a child's socialization and enculturation (Ilari, Chen-Hafteck, \& Crawford, 2013), and defines a person's background (Gaunt \& Hallam, 2009). Regarding the present research, a family's cultural affiliation and level of religiosity may affect their child's participation in musical activities and music learning (Gaunt \& Hallam, 2009). Cultural affiliation can have a significant impact on a child's musical heritage, musical upbringing, and musical learning opportunities (Gaunt \& Hallam, 2009). During childhood, children are exposed to the musical environment of their family (Gaunt \& Hallam, 2009), and when they enter kindergarten and school, they have the opportunity to expand their musical experiences. The educational system provides the children with music lessons that involve a wider age-related scope of experiences, such as singing, playing, listening, improvising, composing, reading and notating, all of which are guided by a music specialist (Abril, 2016; Cutietta, 2002). This type of structured musical exposure within the educational system is characteristic of the school curriculum in many Western societies. Behavior related to teaching music, and to learning and playing it, differs among musical cultures (Campbell \& Wiggins, 2013). In some cultures, the emphasis may be music literacy - reading and playing from notes. Others may

\footnotetext{
* Corresponding author.

E-mail address: ronap.cahn@gmail.com
}

DOI: 10.51865/JESP.2021.2.05 
enhance aural traditions, either in informal settings or formal ones, and there is also the matter of learning individually or with a group. However, musical culture is not only about the making of music - it also refers to the ways and settings of listening to it and to the importance a society accords music and the ideas surrounding it.

The education system in Israel provides formal education from pre-kindergarten to 12th grade (Knesset Research and Information Center, 2013). Placing a child in school depends on the child's native language (Hebrew or Arabic), place of residence, and religious affiliation. In the Jewish sector, the language of instruction in kindergartens is Hebrew, and Arabic in the Arab sector, and the curriculum in each sector is set up to accommodate cultural affiliation, such as the adherence to the religious holidays. Therefore, Jewish children study in Hebrew-speaking kindergartens and schools whereas most Arab children study in Arabic-speaking kindergartens and schools.

The Israeli elementary school curriculum includes a mandatory core curriculum as well as elective curricular subjects (Knesset, 2016). Music education is an elective subject within the arts education curriculum, alongside visual arts, theatre, dance, and communication, and, according to the Israeli Ministry of Education, most Jewish elementary schools (85\%) have music classes as part of the elective curriculum for at least one academic year (Knesset, 2016). However, according to the Chief Supervisor of Music Education in the Ministry of Education, Arab elementary schools have substantially fewer music classes than Jewish schools, although exact numbers are not available. At the secondary and high-school levels, only $10 \%$ of the schools offer music classes.

In Israel, there is a general awareness towards the value of playing a musical instrument while at school. Therefore, there are various national programs supporting instrumental learning (Brand \& Portowitz, 2015). Band and Orchestra are not part of the daily school life, although some high schools in Israel have started to encourage these types of ensembles.

Cultural and religious differences may partially account for the degree to which music education is included in each sector. The Arab population is comprised of Muslim majority of $85 \%$ Muslim, and a 15\% Christian and Druze minority (MyersJDC-Brookdale, 2018). Attitudes toward music differ between the various religions. Generally speaking, the Jewish and Christian religions regard musical activities as an integral part of their culture (Cahn \& Rusu, 2016). However, within the Islam, the debate regarding music dates as far back as the 7th century, following the death of the Prophet Mohammad in 632. It was then that Muslim theologians started to interpret the Quran, also addressing music and musical practices (Cahn \& Rusu, 2016; Shiloah, 1997). While this theological debate did not affect the practice of music in daily life, which includes a great deal of singing and playing that accompany life events (Baily, 2006; Hood, 2007), it did result in two conflicting views regarding music activities one was a permissive view, the other restricted all types of secular musical activities (Shiloah, 1999). The restrictive view was adopted by the leading orthodox Islamic authorities (Baily, 2006; Hood, 2007), and led to restrictions concerning the study and performance of instrumental music (Baily, 2006; Cohen, 1985; Hood, 2007). These restrictions were adopted by the Druze religion as well (Hood, 2007).

Currently, attitudes towards music among Muslims in Arab countries diverge. The majority of Islam orthodox express unfavourable attitudes towards music activities, except for Quran reciting practice, which appears to be very appreciated (Alamer, 2015). Therefore, permission of music in Mosque or in other public spaces might differ between the Arab countries according to the level of population religiosity (Alamer, 2015).

Studies concerning music education career choice, one conducted in the United States (McClellan, 2011) and the other in the UK (Rickels et al., 2013), included students of music who were members of minorities, with about $80 \%$ of the student members of the white majority, and $20 \%$ members of minority groups. McClellan (2011) addressed participants' ethnic heritage distribution, however, the findings dealt with parental influences regarding the decision to become a music teacher with no further findings regarding minorities. Rickels et al. (2013) made no attempt to reveal 
cultural differences or similarities between the ethnic groups, yet they mentioned that having minority students might have contributed to making the program more diversified.

As presented above, in Israel there is a gap in knowledge regarding the differences between the musical upbringing and experiences of the Jewish and Arab societies, which is assumed to be reflected in the decision of young adult individuals towards music education career choice.

\section{Methodology}

\subsection{Objective}

The present research aims to examine the musical background and musical experiences during childhood and adulthood of Israeli Jewish and Arab musiceducation students. Two research questions were formulated: (1) Is there a difference in the type of musical preferences and family involvement in music instrumental studies between Jewish Israeli and Arab Israeli students? (2) Is there a difference in childhood musical experiences between Israeli Jewish and Arab students of music education?

\subsection{Participants}

Participants included 50 Israeli music education students from three academic institutions, 26 (52\%) Jewish and 24 (48\%) Arab, 35 (70\%) women and $15(30 \%)$ men. Sampling was done by convenience, based on the professional network of the first author. Two institutions requested that the questionnaires should be sent by email through their server, while the third institution granted permission to the researcher to hand out the questionnaire on campus. Students were asked to sign a written consent for the participation in the study, in which they were informed about the anonymity of their demographic data and of the responses to the questionnaire. Ethical approval for the data collection was received from the participating institutions. Data were collected in the first semester of the academic year 2017-2018.

\subsection{Instrument and procedure}

The participants filled out the Cultural Attitudes toward Music Experience and Education (CAMEE) questionnaire (Poles Cahn \& Rusu, 2018). CAMEE (Poles Cahn $\&$ Rusu, 2018) is a three-part questionnaire constructed to provide demographic data and examine musical experience during childhood, parental and social encouragement and support, present information regarding the musical experience as a student, cultural aspects regarding general music experience, attitudes toward teaching, and cultural influences. The first part is a demographic questionnaire. In the second part, some of the questions have to be rated on a 6-point Likert scale (1 - not at all, $6-$ very much). An example of such questions is: At home, when you were growing up, did people around you listen to music? The questionnaire also includes binary-answer questions (yes/no), such as: Have you participated in-group music activities in the past? These were followed by explanatory questions referring to the binary answers, for example, If Yes, what were they? (You may specify more than one type of the following ones: Ensemble playing/singing at a music centre or conservatory; Ensemble playing/singing in elementary school; Singing in a choir). The third part of the questionnaire consisted in several open-ended questions, which allowed the participants to answer and to explain their statements (e.g. is it common to study music in your society? Did your society's attitude affect your choice to study music? Would you like to add something?). The answers to these questions were later on qualitatively analysed by using the theme-based content analysis method, but these findings are to be included in a different publication, so there are not presented here.

The computation of the internal consistency (Cronbach's Alpha $=.71$ ) indicates a good reliability of the CAMEE instrument. 


\section{Results}

\subsection{Musical background differences between the two groups}

The participants' self-reported musical background included the following themes: preferred musical genres for listening, musical instruments played, Western and/or Arab music theory studies.

For the first theme, i.e. preferred musical genres for listening, participants were given a list of musical genres, and were asked to indicate all those they listened to in their everyday life. The cluster analysis yielded two clusters of musical preferences (Fig. 1). Although each cluster included almost all musical genres there was a difference in probability that a particular genre would be preferred. Cluster 1 had a higher probability for the Western-style genres than did Cluster 2, where the probability of Arab-style genres was higher, alongside Western music - both classical and popular. Cluster 1 characterized 20 students $(40 \%)$ of whom $73 \%$ were Jewish and one was Arab (4\%). Cluster 2 characterized 30 students (60\%), and included all but one of the Arab students (96\%) and about 27\% the Jewish students.

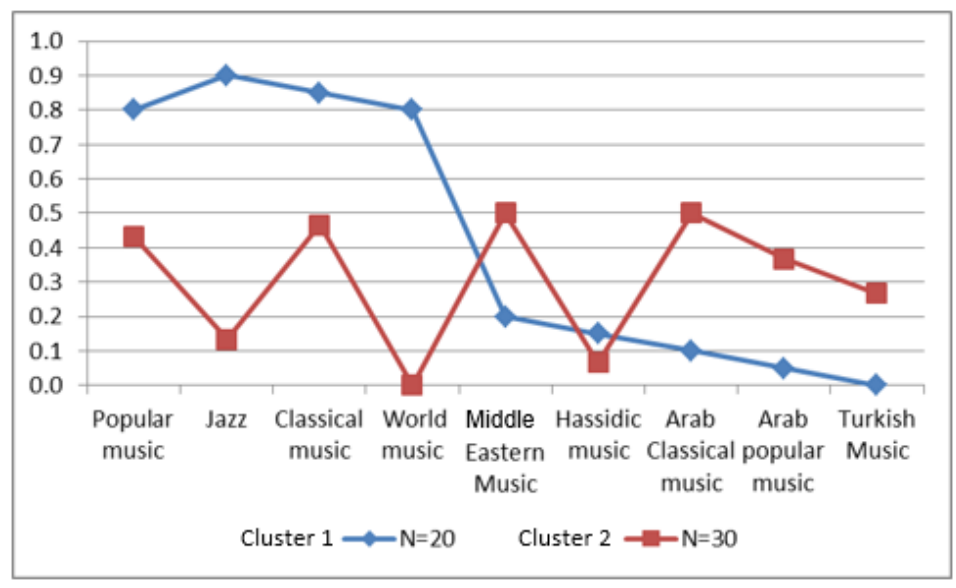

Figure 1. Preferred musical genres for listening clusters

A Chi-square test was conducted to further explore these marked listening preferences between the two groups of participants, using frequency of data to check whether variables are significantly related. According to the null hypothesis, the variables are independent and no associations among them exist. When an association is found, the null hypothesis will be rejected (Gravetter \& Wallnau, 2008), indicating significant associations among the variables. The Chi-square analysis of the preferred musical genres for listening clusters showed significant differences in frequency of distribution $(\chi 2=24.69, \mathrm{p}<.001, \mathrm{~N}=50)$.

For the investigation of the second theme, i.e. musical instruments played, the participants were asked to list their main and secondary musical instruments. The list yielded a total of 12 types of instruments, with seven musical categories: piano, electric keyboard, strings (bass guitar, guitar, and violin), percussion (drums, and darbuka - a Middle Eastern drum), wind (recorder, saxophone, and clarinet), voice, and oud (i.e. typical Middle Eastern stringed musical instrument). The cluster analysis yielded two musical instruments clusters as shown in Figure 2. 


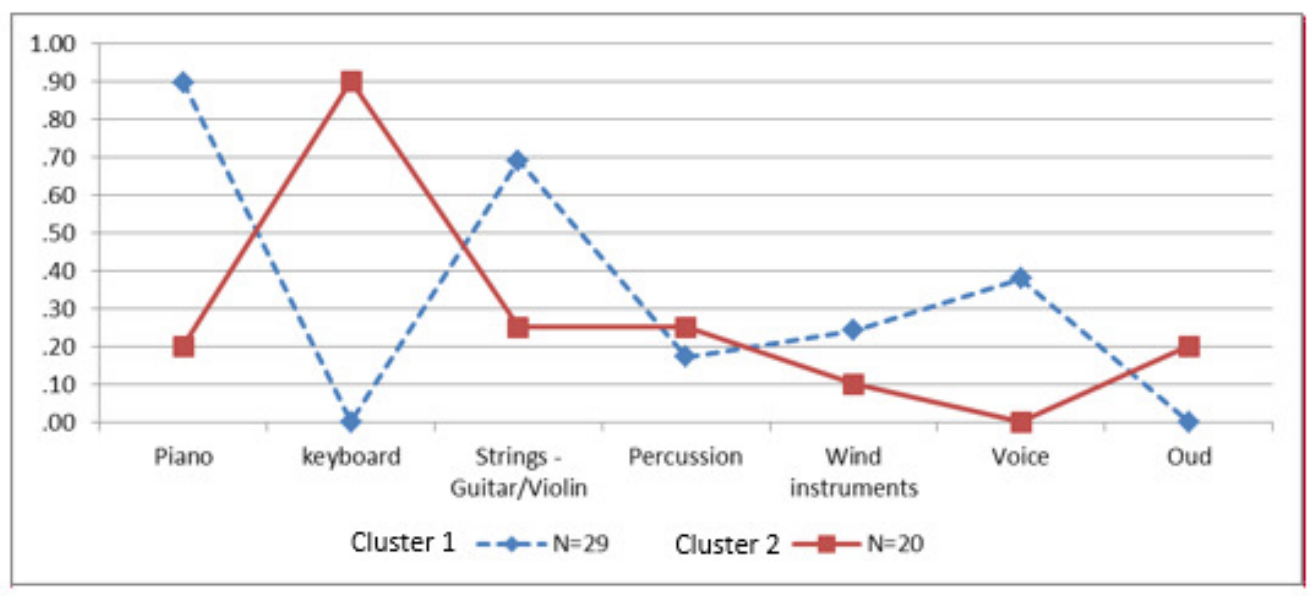

Figure 2. Cluster of musical instruments played during childhood by Jewish and Arab music education students 
As indicated in the figure 2, Cluster 1 had a higher probability for piano, strings, and voice characterized 29 students, and these included almost all the Jewish students $(96 \%)$ and a few of the Arab students (17\%). Cluster 2 had a higher probability for keyboard, strings, and percussion characterized 20 students, and these included most of the Arab students (83\%) and one Jewish student (4\%). Chi-square analysis showed significant differences in frequency of distribution between the two clusters $(\chi 2=$ 31.34, $\mathrm{p}<.001, \mathrm{n}=49$ ).

For the theme Western and/or Arab music theory studies, data analysis revealed significant differences between the groups. Here, $88 \%$ of the Jewish students had studied Western music theory compared to $54 \%$ of the Arab students $(\chi 2=6.90, \mathrm{p}<$ $.01, \mathrm{n}=49$ ), and $88 \%$ of the Arab students studied Arab music theory compared to $8 \%$ of the Jewish students $(\chi 2=31.07, \mathrm{p}<.001, \mathrm{n}=49)$.

\subsection{Musical experiences during childhood and adulthood}

The participants' self-reported musical experiences during childhood and adulthood included the following themes: exposure to music lessons at school, instrumental and vocal learning, ensemble participation as an adult, and public performances with the ensemble.

For the first theme, i.e. exposure to music lessons at school, a high percentage of students from both populations (92\% of the Jewish students and $83 \%$ of the Arab students) reported having had music lessons at school. However, significant differences were found between the groups regarding the availability of school music lessons in first grade $(\chi 2=23.09, \mathrm{p}<.001)$ and second grade $(\chi 2=18.15, \mathrm{p}<.001)$. In both these grades the majority of Jewish students had received music lessons compared to a minority of the Arab students. In the first grade, $85 \%$ of the Jewish students compared to $17 \%$ of the Arab students; in the second grade, $77 \%$ of the Jewish students compared to $17 \%$ of the Arab students.

No significant differences were found regarding the music lessons received in the third to sixth grades (more than half of the Jewish and Arab students had had music lessons at school). No differences were found regarding the music lessons received in the seventh to ninth grades, where few students from both groups attended music lessons. A significant difference was found between the two groups regarding music lessons in high school $(\chi 2=5.98, \mathrm{p}<.05)$, where $31 \%$ of the Jewish students had music lessons compared to $4 \%$ of Arab student.

For the theme instrumental and vocal learning, the Chi-square analysis of responses to the question of whether the students had learned a musical instrument during childhood indicated a significant difference between the Jewish and Arab students $(\chi 2$ $=1.08, \mathrm{p}<.01, \mathrm{~N}=50)$. The majority $(92 \%)$ of the Jewish students had played a musical instrument compared to half of the Arab students (50\%).

The Jewish and Arab students significantly differed regarding the age at which they started playing a musical instrument. The majority (75\%) of the Jewish students began playing a musical instrument between ages 3-9, compared to a minority (23.5\%) of the Arab students (Poles Cahn \& Rusu, 2018). The remaining students from both groups started playing an instrument at an older age, 10-19.

A significant difference was found regarding the number of years in which the participants studied their musical instrument $(\mathrm{t} 33.58=4.02, \mathrm{p}<.001)$. Jewish students took lessons for an average of almost seven years $(M=6.94, S D=4.30)$, Arab students took lessons for an average of almost three years $(M=2.97, S D=1.91)$, a difference of almost four years in average.

As for singing, although no significant differences were found for the frequency of singing activities during childhood, a significant difference was found between the Jewish and Arab students regarding the age at which they started singing (Poles Cahn $\&$ Rusu, 2018). The majority of Jewish students (82\%) started singing between ages 3-9, as compared with half of the Arab students (50\%) (the other Arab students reported that they started singing later in their adolescence).

For the theme ensemble participation as an adult / public performance with the ensemble, there was no difference in the rate of playing in an ensemble between the 
two groups, with $46 \%$ of Jewish students and 36\% Arab students reporting such playing. Significant differences were found between the students regarding the public performances of the ensembles $(\chi 2=5.66 \mathrm{p}<.05)$. All the Jewish students who played in music ensembles reported that they had performed in public, while only about half of the Arab students reported this type of performances.

\section{Discussions}

The aim of the current study was to identify and discuss cultural differences and similarities between Israeli Jewish and Arab music-education students as these are manifested in their musical background and their musical experiences during childhood and adulthood, in relation to their music education career choice. Significant differences were found regarding musical background themes of preferred musical genres for listening, musical instruments played, Western and/or Arab musical theory studies. Overall, the majority of Jewish students listened to Westernstyle genres, played piano, strings and sang, and studied Western musical theory during childhood and adolescence. The majority of Arab students listened to Arabstyle genres as well as Western music - both classical and popular, played keyboard, strings, and percussion and studied Arab music theory. Other significant differences were found between the two groups regarding musical experiences during childhood and adulthood on the themes of exposure to music lessons at school, instrument and vocal learning, ensemble participation as an adult, and public performances with the ensemble.

We are fully aware that these results indicate cultural differences related to music only between the two investigated groups of Jewish and Arab music-education students, based on the data collected on their musical background and musical experiences during childhood and adulthood. Hence, generalization should be done with cautious and more variables should be taken into account when discussing solid cultural differences in relation to music education.

In this study, differences between the two groups of students were identified at levels of the choice of musical instruments and of the type of musical theory studied. The Jewish culture is mainly oriented around Western music, although Jew who emigrated from Arab countries is oriented also toward Arab music. Results of this study exemplified this orientation by the fact that about a quarter of the Jewish students were included in the cluster that had a higher probability of Arab-style genres. The Arab students were mostly oriented toward Arab music thus showing the cultural differences between the two groups of students. One can consider that these differences should not be looked upon as problematic, but rather as a point to address in terms of teaching. Based on these specific results, one can recommend that music from both cultures should be taught as a means of exposing Israeli Jewish and Arab students to different approaches to such musical components such as tonality, form, instruments, texture and scales, as a way to expand their horizons.

Differences regarding musical experiences during childhood include the fact that Arab first graders do not receive music education as part of their curriculum, whereas Jewish first graders do. Furthermore, Jewish high schools have elective music education, which, for the most part, is not offered in Arab schools. Another difference is the smaller number of Arab students who began playing a musical instrument during childhood, a rate lower than among their Jewish counterparts.

Music classes are part of the elective hours that elementary schools may choose to include in their curriculum (Knesset, 2016). The fact that many of the Jewish firstand second-grade students participated in music classes reflects the decision of the school principals to include music class as an elective subject. This decision might indicate the importance attributed to music classes within the Jewish society in Israel, whereas the fact that most Arab students did not have a music class in the first two grades of elementary school, may be indicative of the lower importance attributed to music studies in Arab society. The debate regarding music learning in religious Muslim Arab population (Shiloah, 1999; Poles Cahn \& Rusu, 2018) may affect the 
popularity of music learning among Arab children as well as the availability of music classes in school.

As seen, about a third of the Jewish students had studied in high-school music programs, and one Arab student did so, too. This may be due to the fact that there are currently 135 high schools in the Jewish sector that offer music programs, and 6 in the Arab sector. The music programs in the Arab high schools are relatively new, perhaps indicating a change of attitude toward music studies in Arab society.

The results showed that significantly fewer Arab students played a music instrument during childhood than did Jewish ones, and that those who did study, began doing so at a significantly later age than the Jewish students. On average, the Jewish students had taken music lessons for almost seven years during childhood, compared to almost three years amongst the Arab students. Additionally, the singing activity amongst the Jewish students began at a significantly earlier age than amongst the Arab students.

The lack of appreciation of learning music may partially explain the smaller number of Arab music education students who had had musical training in their childhood. In terms of geography, $60 \%$ of the Arab population live in rural areas (Gharrah, 2013) where, as mentioned in the quote above, there is a lack of a music institutions and music teachers. This type of reality obviously prevents the availability of music studies. Finally, the economic state of the Arab population, which is reported to be $40 \%$ lower than the Jewish population (Gharrah, 2013), suggests that financial considerations could affect the decision to invest in music education outside of the school system.

Although the findings show differences in musical upbringing between the Jewish and Arab students, it seems that changes are taking place within Israeli Arab society. These changes are manifested in the afore-mentioned high-school music programs that were opened in six Arab schools since 2015, and by the fact that Israeli Arab students are enrolled in music education programs and are later employed within the Arab schools. Music learning in Arab society is more accepted today than it was in the past in Israel. Karkabi (2013) described a young generation of Arab individuals in their twenties and thirties who are consumers of music and look for places to celebrate their music. Abdel-Rahman Hamza (2014) described parents in their thirties who are in favor of music lessons for their children as part of the school curriculum. The Arab students who pursue a music education career are spearheading the change in attitude toward music education in their society.

Practical implications of this research include the recommendation to promote children's instrumental learning from a younger age, as well as music learning in the Arab schools in Israel. A possible action to take in order to achieve that can be through initiating contact with Arab community leaders such as school principals and religious leaders in order to present them with the positive psychological and societal benefits of music making for children. Their approval may create a better acceptance towards music learning in their communities. Furthermore, more music programs should be made available in rural areas in Israel. The current change that is taking place within the Arab sector could be seen as a process in progress towards the societal approval of music learning. In line with these promising changes, an important dimension that could be addressed through the pre-service teacher programs is the awareness of the students in music education towards the importance of the teachers' support that is perceived by the children, particularly the enthusiasm of the teacher (Vidic \& Duranovic, 2020), in those schools were new programs in music education have been recently introduced. 


\section{References}

1. Abdel-Rahman Hamza, D. (2014). Parents' perceptions of music classes in an elementary school: case Arabic elementary school in northern Israel. Unpublished master's thesis, Levinsky College of Education, Tel Aviv, Israel (in Hebrew).

1. Abril, C. R. (2016). Untangling general music education. In Abril, C. R. \& Gault, B. M. Teaching general music. NY, USA: Oxford University Press.

2. Alamer, S. M. (2015). Cultural perspectives of associating music with the giftedness in Saudi Arabia. Canadian Social Science, 11(2), 8-15.

3. Baily, J. (2006). Music is in our blood: Gujarati Muslim musicians in the UK. Journal of Ethnic and Migration Studies, 32(2), 257-270.

4. Brand, E. \& Portowitz, A. (2015). Music teaching in Israel. In S. Figueiredo, J. Soares \& R.F. Schamberck (Eds.) The preparation of music teachers: A global perspective. Porto Alegre, Brasil: ANPPOM.

5. Cahn, P. R. \& Rusu, A. S. (2016). Diverse attitudes of religious cultures in Israel towards music and music education. The European Proceedings of Social \& Behavioral Sciences, 18, 552-561. http://dx.doi.org/10.15405/epsbs.2016.12.68

6. Campbell, P. S. \& Wiggins, T. (2013). Giving voices to children. In P.S. Campbell \& T. Wiggins (Eds.), The Oxford handbook of children's musical cultures. Oxford: Oxford University Press.

7. Cohen, D. (1985). East and West in music. Jerusalem: Hebrew University Press.

8. Cutietta, R. A. (2002). Raising musical kids. Oxford: Oxford University Press.

9. Gaunt, H. \& Hallam, S. (2009). Individuality in the learning of musical skills. The Oxford Handbook of Music Psychology. Oxford, UK: Oxford University Press.

10. Gharrah, R. (2013). Arab society in Israel (6): Population, society, economy. Jerusalem: Van Leer and Hakibbutz Hameuchad (in Hebrew).

11. Hood, K. (2007). Music in Druze life. London, UK: Druze Heritage Foundation.

12. Ilari, B., Chen-Hafteck, L. \& Crawford, L. (2013). Singing and cultural understanding: A music education perspective. International Journal of Music Education, 31(2), 202-216.

13. Karkabi, N. (2013). Staging particular difference: Politics of space in the Palestinian alternative scene. Middle East Journal of Culture and Communication, 6, 308-328.

14. Knesset Research and Information Center (2013). Educational system in Israel main subjects dealt in the Education, Culture and Sport Committee. Retrieved from http://www.knesset.gov.il/ (in Hebrew).

15. Knesset Research and Information Center (2016). Conservatories and their place in music education in the education system. Retrieved from https://www.knesset.gov.il/ (in Hebrew).

16. McClellan, E. R. (2011). Relationships among parental influences, selected demographic factors, adolescent self-concept as a future music educator, and the decision to major in music education. Bulletin of the Council for Research in Music Education, 18, 49-64.

17. Myers-JDC-Brookdale (2018). The Arab population: Facts and numbers 2018 (Hebrew).

18. Poles Cahn, R., \& Rusu, A. S. (2018). A comparison between the musical upbringing of Jewish and Arab students in Israel. The European Proceedings of Social \& Behavioral Sciences, 231-240. doi: http://dx.doi.org/10.15405/epsbs.2018.06.28

19. Rickels, D. A., Brewer, W. D., Councill, K. H., Fredrickson, W. E., Hairston, M., Perry, D. L., Porter, A. M., \& Schmidt, M. (2013). Career influences of music education auditioncandidates. Journal of Research in Music Education, 61, 115-134.

20. Shiloah, A. (1997). Music and religion in Islam. Acta Musicologica, 69(2), 143-155.

21. Shiloah, A. (1999). Music in the world of Islam. Jerusalem, Israel: Bialik Institute (in Hebrew).

22. Vidic, T. \& Duranovic, M. (2020). Students' attitudes towards mathematics and their perception of teacher support, enthusiasm, classroom management and their own behaviors. Journal of Educational Sciences and Psychology, 10(2), 61-73.

23. Byrne, B. M. (1984). The general/academic self-concept nomological network: A review of construct validation research. Review of Educational Research, 54, 427-456

24. Byrne, B. M., \& Worth Gavin, D. A. (1996). The Shavelson model revisited: Testing for the structure of academic self-concept across pre-, early, and late adolescents. Journal of Educational Psychology, 88, 215-228.

25. Leary, M.R., Tangney, J.P. (2003). Handbook of self and identity. New York: Guilford Press. 